
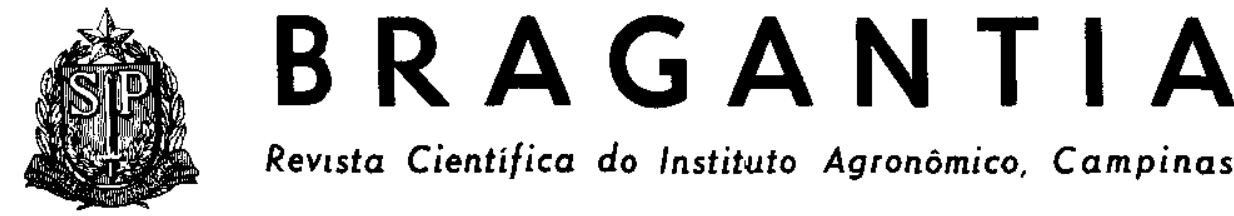

Revısta Cientifica do Instituto Agronômico, Campinas

\title{
COMPORTAMENTO DE CLONES DE CANA-DE-AÇÚCAR EM RELAÇÃO A DIATRAEA SACCHARALIS (FABR., 1794)
}

André lutz Lourenção $\left({ }^{2}\right)$, Carlos Jorge Rossetto, Seção de Entomologia Fitotécnica, Emílio Bruno Germek, Seção de Botânica Econômica, Toshio IgUe, Seção de Técnica Experimental e Cálculo, Jorge Alberto Marques ReZende ( ${ }^{2}$ ), Seção de Virologia Fitotécnica, e José Cardos Vila Nova Alves Pererra, Estação Experimental de Ribeirão Preto, Instituto Agronômico.

\section{RESUMO}

Avaliou-se o comportamento de dezesseis introduções, consideradas resistentes à broca no Sul dos E.U.A., e quatro clones 'IAC' de cana-de-açúcar em relaçăo ao ataque de Diatraea saccharalis (Fabr., 1794) (Lepidoptera:Pyralidae) em ensaio delineado em blocos ao acaso, com dez repetiçōes, instalado na Estaçāo Experimental de Ribeirão Preto, do Instituto Agronómico. As introduçōes utilizadas foram CP57-614, CP62-258, CP66-491, CP70-321, CP70-330, CP71-321, Tainan 2n $=96$, US74-103, US76-9, US-76-14, US76-15, US76-20, US76-22, US76-25, US76-26 e US76-34 e, os clones, 'IAC50-134', 'IAC52150', 'IAC71-1001' e 'IAC1006'. Decorrido um ano do plantio, efetuado em setembro de 1979, procedeu-se à avaliaçấo. Vinte colmos por parcela foram cortados e, individualmente, mediu-se o diâmetro e contaram-se os internódios sadios e broqueados. A partir desses dados, calcularam-se a infestaçấo e a sua intensidade. Os dois indices evidenciaram o mais baixo ataque de $\mathbf{D}$. saccharalis na introdução Tainan $2 \mathrm{n}=96$, cujo diâmetro médio foi $1,03 \mathrm{~cm}$, e o ataque mais alto no cultivar IAC52-150, de diâmetro médio $2,83 \mathrm{~cm}$. Correlacionando-se o diâmetro com os indices de infestaçāo nos vinte clones, verificou-se que a infestaçâo é diretamente proporcional ao diâmetro $\left(r^{2}=0,91\right)$ e, a intensidade, ao quadrado do diâmetro $\left(r^{2}=0,82\right)$. No Brasil, a possibilidade de utilização desse germoplasma introduzido dos E.U.A. como fonte de resistência a D. saccharalis é incerta, em face da associação observada entre infestaçāo e diâmetro das plantas.

\section{INTRODUÇĀO}

A broca do colmo, Diatraea saccharalis (Fabr., 1794) (Lepidop-
tera:Pyralidae), a mais conhecida espécie do gênero atacando cana-de-açúcar (5), encontra-se amplamente

(1) Trabalho apresentado no $7 .^{\circ}$ Congresso Brasileiro de Entomologia, realizado em Fortaleza (CE), de 12 a 17 de julho de 1981. Recebido para publicação a 18 de agosto de 1981 . Os autores agradecem a Aldo Fernandes, Archangelo Marion, Joāo Luiz da Silva, José Fernando Marion, Maria Inês Fonseca Jorge, Osvaldo Federicci e Valter J. L. Morgado, da Seção de Entomologia do IAC, o auxílio na execução do trabalho, e aos Drs. R. D. Jackson e J. E. Irvine, USDA Sugarcane Research Station, Houma, Louisiana, o fornecimento dos clones de cana.

(8) Com bolsa de suplementaçāo do $\mathrm{CNPq}$. 
distribuída na região neotropical, ocorrendo desde o Sul dos EUA até o Norte da Argentina $(5,6,9)$.

No Brasil, tanto D. saccharalis como D. flavipennella, outra broca da cana-de-açúcar, estão presentes em todas as regiões canavieiras, com exceção do Estado de São Paulo, onde apenas a primeira ocorre (18).

Os prejuízos causados por brocas em cana-de-açúcar normalmente são consideráveis. De acordo com MATHES \& CHARPENTIER (15), esses danos se referem a falhas na brotação em função da morte de gemas em toletes atacados, ao "coração morto" em plantas jovens, ao ponteiro morto em plantas velhas, a colmos broqueados, ao desenvolvimento reduzido nos colmos atacados que sobreviveram e a perdas na qualidade da cana. Afirmam os AA. que o ataque da broca ao colmo pode diminuir, além da quantidade de caldo extraível, sua porcentagem de sacarose, sua pureza e o total de não-açúcares orgânicos. A cor do caldo e do xarope clarificados torna-se mais escura. A deterioração resultante da ação direta da broca é aumentada pela penetração de fungos e bactérias nas galerias. Finalmente, relatam que o dano da broca atrasa a maturação.

O uso de cultivares de cana-de-açúcar resistentes a brocas é a opção ideal de controle, integrando-se perfeitamente com outros métodos como, principalmente, o emprego de inimigos naturais.

\section{MATHES \& CHARPENTIER} (15) assinalaram que a resistência de cana-de-açúcar a brocas pode resultar de um ou mais dos seguintes fatores: a) não atratividade da planta hospedeira à oviposição dos adultos; b) caracteres desfavoráveis da planta ao estabelecimento de brocas em seu interior; c) caracteres da planta que inibem ou retardam o desenvolvimento da broca, e d) tolerância ou habilidade da planta em produzir bem, mesmo com alta infestação. Antibiose, conforme a terminologia proposta por PAINTER (17), inclui os itens b e c. Todavia, aqueles autores reconheceram a dificuldade de separar qualquer um dos fatores que conferem resistência a brocas em meio a tantos caracteres envolvidos no processo. Apesar de alguns caracteres agronomicamente indesejáveis estarem correlacionados com resistência a brocas, exceções suficientes ocorrem, permitindo que, através de cruzamentos, se combine a resistência com boas qualidades agronômicas (14).

Existem na literatura trabalhos que tratam da resistência varietal de cana-de-açúcar a D. saccharalis. GALLO (7) estudou o comportamento de seis cultivares de cana-planta em relação ao ataque dessa broca e verificou que o 'CB36-24' foi o menos infestado. AMARAL \& ARRUDA (2), avaliando quinze cultivares quanto ao ataque da broca em cana-planta, soca e ressoca, verificaram também que 'CB36-24' se situou entre os menos suscetíveis, juntamente com 'CB46-5' e 'Co331'. Verificaram ainda que o terço médio do colmo foi a parte preferida pela broca e que a cana-planta foi mais atacada que a soca e ressoca. Em ensaio posterior com dez cultivares, os dois autores (3), avaliando apenas colmos do primeiro corte, observaram que 'CB41-15' e 'IAC48-65' apresentaram menor dano de D. saccharalis. 
Através de infestação artificial dessa broca em 31 clones de Saccharum spontaneum, JACKSON \& DUNCKELMAN (10) observaram que Tainan $2 n=96$ e US56-8-2 não foram danificados pelo inseto, ao passo que as testemunhas NCo310 e CP52-68 foram as mais atacadas.

MACEDO et alii (12) estudaram a suscetibilidade dos dezesseis cultivares mais cultivados na região Centro-sul a esse inseto. A pesquisa realizada em quatro locais, em cana-planta, soca e ressoca, indicam IAC50-134, CB45-155, CB56-156 e Co775 como os mais resistentes e IAC52-150, CP51-22, NA56-62, IAC52-326 e CB41-76 como os mais suscetíveis. Verificaram esses AA., a exemplo de AMARAL \& ARRUDA (2), que a cana de primeiro corte é a mais atacada.

Pesquisas efetuadas pelo PLANALSUCAR (19) apontaram IAC 48-65, CB45-155, IAC50-134, CB 47-355, Co775 e CB56-171 como os cultivares menos atacados pela broca, e IAC52-150, CP51-22, NA56-79 e NA56-30, como altamente suscetíveis.

BASTOS et alii (4), avaliando a infestação de D. saccharalis em 30 clones em cana-planta e soca, verificaram existir influência dos progenitores no comportamento da progênie, uma vez que houve tendência de Co419 e IAC52-179 em originar clones resistentes à broca, de CB40-69 em produzir clones suscetíveis, e de CB40-35 em produzir clones com grande variação na infestação.

MATHES et alii (16), estudando - comportamento de progênies de cruzamentos de cana-de-açúcar em relação a D. saccharalis, investigaram a possível associação de certas características morfológicas da planta com o dano da broca. Observaram que a porcentagem de internódios broqueados foi diretamente proporcional ao diâmetro do colmo $e$ inversamente proporcional à altura da planta. que não existiu relação entre a porcentagem de internódios broqueados e largura das folhas e que os colmos brancos e rosados foram significativamente menos danificados que os verdes.

Em face da importância de D. saccharalis como principal praga da cultura de cana-de-açúcar $(\mathbf{8}, 13)$ e das pesquisas de clones resistentes a esse inseto em programas de melhoramento de cana-de-açúcar nos E.U.A. (10, 11), procurou-se introduzir e estudar esses clones frente à broca em condições brasileiras.

\section{MATERIAL E METODOS}

Os clones utilizados no ensaio estão listados no quadro 1. As introduções do grupo US apresentam alta proporção de genes de S. spontaneum e foram originadas através de cruzamentos entre Tainan $2 \mathrm{n}=96$ (pertencente à espécie $\mathbf{S}$. spontaneuni) e NCo310. Este genótipo tem como pais Co421 e Co312, os quais descendem de três espécies, $\mathbf{S}$. officinarum, S. spontaneum e $S$. sinense. As introduções do grupo CP são híbridas de Saccharum spp. e constituem, junto aos clones do grupo US e Tainan $2 \mathrm{n}=96$, os clones selecionados para resistência à broca $D$. saccharalis no United States Department of Agriculture, Sugarcane Research Station, Houma, Louisiana. A introdução desses clones foi efetuada pelo terceiro autor através do Setor de Intro- 
dução de Plantas, da Seção de Botânica Econômica do Instituto Agronômico, Campinas, a pedido da Seção de Entomologia. Eles foram introduzidos a $4 / 9 / 76$, ficaram quarentenados durante catorze meses em casa de vegetação da Seção de Botânica, sendo liberados em 8/11/77 e então multiplicados em canteiros no Centro Experimental de Campinas.

Os cultivares brasileiros IAC 50-134 e IAC52-150, híbridos de Saccharum spp., são considerados, respectivamente, resistente e suscetível a $D$. saccharalis $(12,18,19,21)$. IAC71-1001 e IAC1006 constituem material que se pretende conhecer quanto ao seu potencial para fins de melhoramento, sendo que IAC 71-1001, com alta carga de genes de S. spontaneum, apresenta colmos finos em relação aos outros três clones utilizados do grupo 'IAC', conforme se vê no quadro 1 .

Toletes dos vinte clones foram plantados a 26/09/79 em área da Estação Experimental de Ribeirão Preto, do Instituto Agronômico, utilizando-se o delineamento estatístico de blocos ao acaso, com vinte tratamentos e dez repetições. Cada parcela foi constituída de uma linha de $3,00 \mathrm{~m}$, com espaçamento de $1,50 \mathrm{~m}$ entre parcelas e $2,00 \mathrm{~m}$ entre blocos. A fim de se isolar o ensaio, usou-se o cultivar CB41-76 ao redor da área experimental. Plantaram-se duas linhas de $56,00 \mathrm{~m}$ em cada lado do campo e, em cada extremidade, vinte linhas de $2,00 \mathrm{~m}$ cada uma, no mesmo sentido das parcelas.

As plantas ficaram expostas à infestação natural de $\mathbf{D}$. saccharalis até $06 / 09 / 80$, quando se procedeu à avaliação. De cada parcela, foram cortados ao acaso vinte colmos e, individualmente, mediu-se $o$ diâmetro e contaram-se os internódios sadios e broqueados. A partir desses dados, calcularam-se a infestação e a sua intensidade, conforme GALLO et alii (8) e GUAGLIUMI (9). A infestação foi obtida através da porcentagem de colmos atacados em relação ao total de examinados de cada parcela, não interessando o número de internódios broqueados dos colmos atacados. Para análise, os valores foram transformados em arco seno $\sqrt{\mathbf{P} / 100}$, sendo $P$ a porcentagem, obtidas as médias e aplicado o teste de Duncan ao nível de $5 \%$. A intensidade de infestação foi determinada pelo cálculo da porcentagem de internódios broqueados entre o total de examinados na parcela. Os valores foram convertidos em logaritmo $(\mathrm{X}+0,5)$ e as médias comparadas pelo teste de Duncan ao nível de $5 \%$. Foram ajustadas equações de regressão linear e quadrática respectivamente para infestação e intensidade de infestação a partir das médias obtidas entre as dez repetições de cada tratamento. Consideraram-se a infestação e a intensidade como variáveis dependentes e o diâmetro do colmo como variável independente.

\section{RESULTADOS E DISCUSSÃO}

O quadro 1 apresenta os clones avaliados em relação ao ataque de D. saccharalis, os diâmetros médios dos colmos, as médias de intensidade de infestação reais e transformadas em logaritmo $(X+0,5)$, as médias de infestação reais transformadas em arco seǹo $\sqrt{\mathbf{P} / 100}$ e o teste de Duncan aplicado às médias transformadas desses dois índices. 


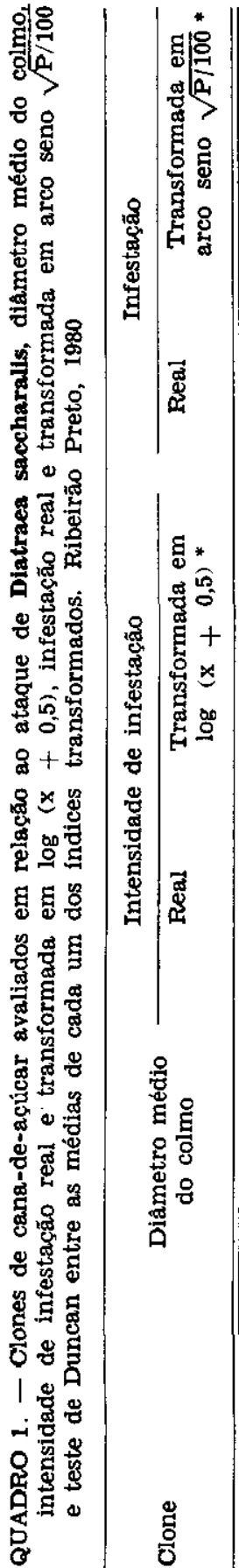

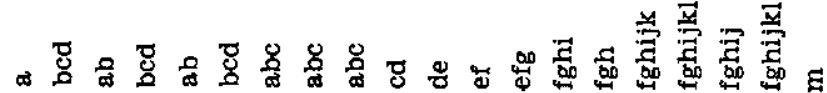

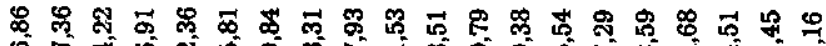

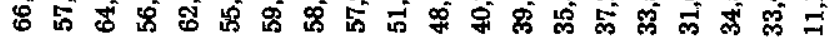

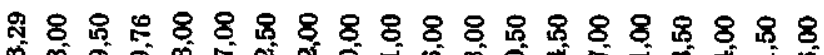

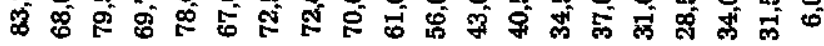

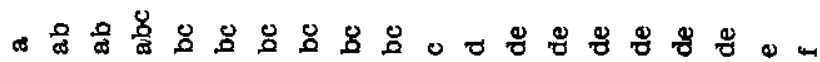

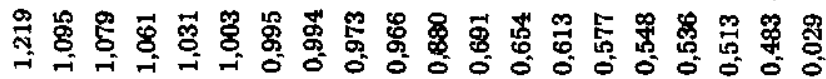

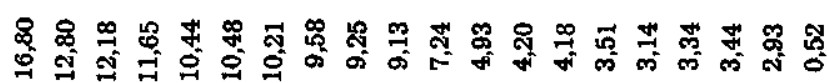

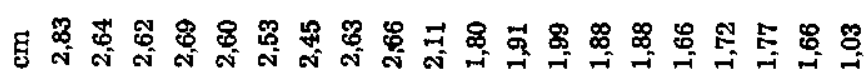


A comparação das médias de infestação e de intensidade de infestação, através do teste de Duncan, mostrou que os clones apresentam graus diferentes de dano à broca. Os dois índices evidenciaram o cultivar IAC52-150 como o mais infestado, confirmando observações anteriores $(12,18,19)$ e indicaram a introdução Tainan $2 \mathrm{n}=96$ como a menos infestada, o que concorda com os resultados de JACKSON e DUNCKELMAN (9). Já o cultivar IAC 50-134, citado como portador de resistência a D. saccharalis $(\mathbf{1 2}, \mathbf{1 8}$, 19, 21), foi o segundo tratamento mais danificado pela broca, de acordo com as médias de intensidade de infestação.

Cotejando-se os dois índices com o diâmetro médio do colmo, verifica-se que existe uma relação direta entre dano da broca e diâmetro, ou seja, há tendência de os clones com colmo de diâmetro maior serem mais broqueados que os de diâmetro menor. A introdução Tainan $2 \mathrm{n}=96$. que possui os colmos mais finos, e o cultivar IAC52-150, os mais grossos, foram, respectivamente, os clones menos e mais atacados entre todos os tratamentos, sendo que os restantes sofreram danos proporcionais aos seus diâmetros. As introduções do grupo US, que possuem colmos mais finos que as do grupo $\mathrm{CP}$, foram menos broqueadas que estas, confirmando observação de JACKSON et alii (10). Os clones IAC1006 e IAC71-1001, que são os genótipos mais rústicos do grupo IAC testado, apresentaram comportamentos distintos; o último, com alta proporção de genes de $\mathbf{S}$. spontaneum, caracterizado por possuir colmos finos, situou-se entre os clones menos infestados. Já IAC1006, com colmos de diâmetro maior, foi significativamente mais atacado por D. saccharalis que IAC 71-1001.

Pelo exame da análise da variância para o índice infestação quadro 2 -, verifica-se que a regressão linear com o diâmetro (D) pode explicar $91,2 \%$ das variaçóes encontradas entre os clones. Isso sugere que a relação entre infestação e diâmetro do colmo pode ser representada linearmente, sendo a equação encontrada no presente experimento para essa regressão, $y=-38,32+$ $+42,49 \mathrm{D}$, cujo gráfico é apresentado

QUADRO 2 - Análise da variância para infestação de Diatraea saccharalis, correlacionada com diâmetro do colmo, em vinte clones de cana-de-açúcar. Ribeirão Preto, 1980

\begin{tabular}{lrrrr} 
Fonte de variação & G L. & S.Q. & Q.M. & F \\
\hline Clone & $(19)$ & 50204,2 & 4747,6 & $26,2^{* *}$ \\
Regressão linear (D) & 1 & 82301,3 & $\mathbf{8 2 3 0 1 , 3}$ & $454,4^{* *}$ \\
Desvio de regressão & 18 & 7902,9 & 439,1 & $2,4^{* *}$ \\
Blocos & 9 & 3305,3 & 367,2 & $2,0^{*}$ \\
Erro & 171 & 30963,7 & 181,1 & \\
\hline
\end{tabular}


na figura 1. Dessa forma, o índice infestação ficou relacionado diretamente com o diâmetro.

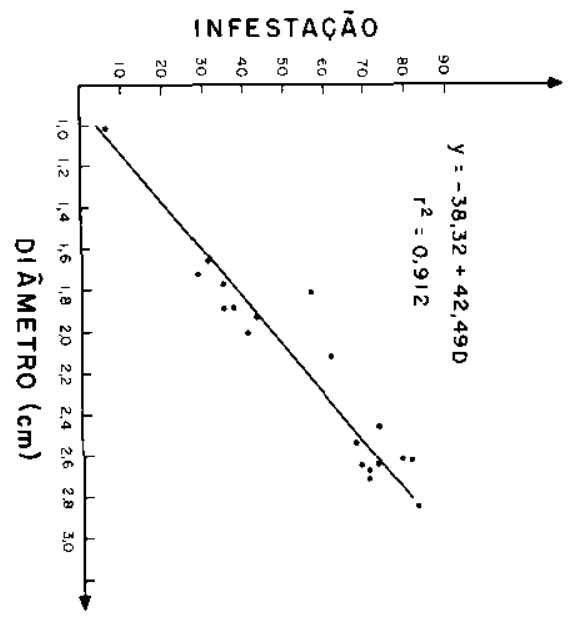

Figura 1. - Regressảo das médias de infestaçăo de Diatrace saccharalis para diâmetro médio de vinte clones de cana-de-açúcar. Ribeirảo Preto, 1980.

Pelo quadro $3,-$ análise da variância para intensidade de infestação - verifica-se que $82,5 \%$ da variação devida ao efeito varietal pode ser explicada pelo componente $\mathrm{D}^{2}$ (quadrado do diâmetro).

A figura 2 traz a equação de regressão quadrática ajustada, $\mathrm{y}=$ $-2,17+1,99 D^{2}$, e sua respectiva

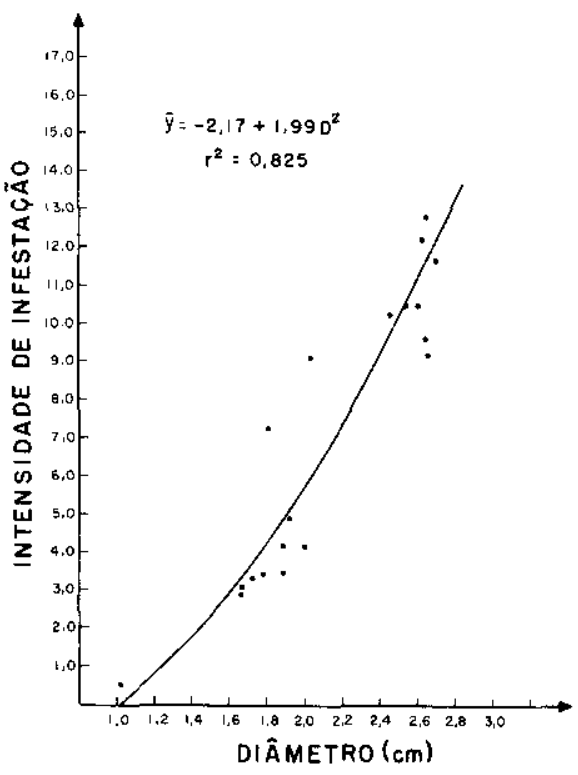

Figura 2. - Regressăo das médias de intensidade de infestação de Diatraea saccharalis para diâmetro médio de vinte clones de cana-de-açúcar. Ribeirảo Preto, 1980.

QUADRO 3 - Análise da variância para intensidade de infestação de Dlatraea saccharalis, correlacionada com o quadrado do diâmetro do colmo, em vinte clones de cana-de-açúcar. Ribeirăo Preto, 1980

\begin{tabular}{|c|c|c|c|c|}
\hline Fonte de variaçāo & G.L. & S.Q. & Q.M. & $\mathbf{F}$ \\
\hline Clone & (19) & 3554,2 & 187,1 & $21,2 * *$ \\
\hline Regressão quadrática $\left(\mathrm{D}^{2}\right)$ & 1 & 2931,7 & 2931,7 & $333,1 * *$ \\
\hline Desvio de regressão & 18 & 622,5 & 34,5 & $3,9^{* *}$ \\
\hline Blocos & 9 & 119,1 & 13,2 & 1,5 n.s. \\
\hline Erro & 171 & 1504,3 & 8,8 & \\
\hline Total & 199 & 5177,6 & & \\
\hline
\end{tabular}


curva, indicando uma correlação direta entre a intensidade de infestação e o quadrado do diâmetro.

Resultados semelhantes foram obtidos por MATHES et alii (16), que, estudando o comportamento de progênies de cruzamentos de cana-de-açúcar em relação à broca, verificaram que a intensidade de infestação foi diretamente proporcional ao diâmetro do colmo. Na revisão feita por AGARWAL (1) sobre características morfológicas da planta de cana-de-açúcar relacionadas com o ataque de insetos, esse é o único trabalho citado em que a infestação de D. saccharalis foi correlacionada com o diâmetro das plantas.

$\hat{E}$ interessante notar que, nessas mesmas introduções, a correlação entre diâmetro e infestação não ocorreu para a cochonilha Saccharicoccus sacchari (Cockerell, 1895) (Homoptera:Pseudococcidae) (20), embora ambas as pragas ataquem o colmo da planta. Seria desejável saber o comportamento de outras pragas da cana-de-açúcar em relção a esse fator morfológico da planta.

Pelos presentes resultados, não há possibilidade de saber se o diâmetro por si só ou algum fator a ele associado é o responsável pelas diferenças na infestação. Pode-se supor que ocorra efeito pleiotrópico, em que os mesmos genes responsáveis pelo diâmetro sejam também responsáveis pelas causas das variações no dano da broca. E possível, também, que ocorra ligação gênica, sendo dois ou mais genes, localizados muito próximos no mesmo cromossomo, responsáveis por cada caráter, diâmetro e causas de suscetibilidade à broca, separadamente.
Se o caso for de pleiotropia, é impossível a utilização desses clones de colmo fino em programa de melhoramento que vise à obtenção de cultivares de colmo grosso e resistentes à broca. Por outro lado, se ocorrer ligação gênica, após o cruzamento de um clone de colmo fino pouco atacado com outro de colmo grosso e mais atacado, deve-se procurar selecionar entre as plantas descendentes apenas as que apresentarem colmos grossos e sejam pouco infestadas, as quais seriam resultantes de "crossing-over", com separação ou quebra dessa ligação.

\section{CONCLUSÕES}

Com base nos resultados obtidos nas condições experimentais, pode-se concluir que:

a) Em experimentação de resistência de cana-de-açúcar à broca D. saccharalis, o diâmetro do colmo dos clones estudados deve ser considerado, pois este fator morfológico apresenta alta correlação com os índices de infestação.

b) $O$ índice infestação apresentou correlação direta e positiva com o diâmetro do colmo da planta (correlação linear).

c) $\mathrm{O}$ índice intensidade de infestação apresentou correlação direta e positiva com o quadrado do diâmetro do colmo da planta.

d) Clones de cana-de-açúcar de colmo grosso e portadores de fatores de resistência a D. saccharalis devem ser preferencialmente utilizados nos programas de melhoramento contra essa praga. 


\section{PERFORMANCE OF SUGARCANE CLONES IN RELATION TO THE SUGAR CANE BORER, DIATRAEA SACCHARALIS (FABR, 1794)}

\section{SUMMARY}

Sixteen clones of sugarcane resistant to the sugarcane borer, D. saccharalis in Houma, Louisiana, USA, were introduced and tested in Brazil against the same insect species.

The sixteen introduced germplasm were CP57-614, CP62-258, CP66-491, CP70-321, CP70-330, CP71-321, Tainan 2n $=96$, US74-103, US76-9, US76-14, US76-15, US76-20, US76-22, US76-25, US76-26 e US76-34.

These sixteen introductions plus 4 IAC clones, namely 'IAC50-134', 'IAC52-150', 'IAC71-1001' and 'IAC1006', were planted on September 26, 1979, in Ribeiräo Preto, State of São Paulo, Brazil. The experimental design used was a complete randomized block with 20 treatments and 10 replications.

Evaluation was made on September 9, 1980. Twenty culms per plot were split lenghtwise and the numbers of internodes bored and not bored were registered.

The variation of infestation among the clones was highly correlated with the diameter of the plants. The least infested germplasm was Tainan $2 \mathrm{n}=96$ with a culm diameter of $1.03 \mathrm{~cm}$. The most infested, IAC52-150 had a diameter of $2.83 \mathrm{~cm}$.

The infestation (percentage of culms infested) was linearly correlated with the diameter $\left(r^{2}=0.91\right)$ and the intensity of infestation (percentage of internodes infested) was linearly correlated with the square of the diameter $\left(r^{2}=0.82\right)$.

These results show the possibility of the use of thinner less infested clones introduced from USA as source of resistance to the sugarcane borer in Brazilian breeding programs.

\section{REFERENCIAS BIBLIOGRAFICAS}

1. AGARWAL, R. A. Morphological characteristics of sugar cane and insect resistance. Entomologia Experimentalis et Applicata, Amsterdam, 12:767-776, 1969.

2. AMARAI, S. F. \& ARRUDA, H. V. Grau de suscetibilidade de 15 variedades de cana-de-açúcar à broca Diatraea saccharalis (F. 1794) (Lepidoptera-Crambidae). Arquivos do Instituto Biológico, São Paulo, 31(3):79-83, 1964.

3. —_ Suscetibllidade de novas variedades de cana-de-açúcar à Diatraea saccharalis (F. 1794) (Lepidoptera-Crambidae). O Biológico, São Paulo, $38(3): 73-75,1972$.

4. BASTOS, C. R.; POMMER, C. V.; NELLI, E. J. Avaliaçāo de clones de cana-de-açúcar para resistência à broca do colmo Diatıdea saccharalis (Fabr., 1794). Ecossistema, Espírito Santo do Pinhal, 5:71-77, 1980.

5. BLESZYNSKI, $S$. The taxonomy of the Crambinae moth borers of sugar cane. In: WILLIAMS, J. R.; METCALFE, J. R.; MUNGOMER, R. W.; MATHES, R., eds. Pests of sugar cane. New York, Elsevier, 1969. p.11-41.

6. BOX, H. E. The Crambinae genera Diatraea and Xanthopherne (Lep., Pyral.). Bulletin of Entomological Research, London, 22:1-50, 1931.

7. GALLO, D. Infestação da broca nas principais variedades de cana. Revista de Agricultura, Piracicaba, 29(5-6):149-155, 1954.

8. - N NAKANO, O.; SILVEIRA NETO, S.; CARVALHO, R. P. L.; BATISTA, G. C. de; BERTI F.o, E.; PARRA, J. R. P.; ZUCCHI, R. A.; ALVES, S. B. Manual de entomologia agrícola. Säo Paulo, Ceres, 1978. 531p. 
9. GUAGLIUMI, P. Pragas da cana-de-açúcar - Nordeste do Brasil. Rio de Janeiro, Instituto do Açúcar e do Alcool, 1972/73. 622p. (Coleção Canavieira, 10)

10. JACKSON, R. D. \& DUNCKELMAN, P. H. Relative resistance of Sacrum spontaneum clones to the sugar cane borer. In: CONGRESS OF THE INTERNATIONAL SOCIETY OF SUGAR CANE TECHNOLOGISTS, 15., Durban, 1974. Proceedings. p.513-515.

11. —— Mc CORMICK, W. J.; BREAUX, R. D.: DUNCKELMAN, P. H. Evaluation of sugar cane varieties for borer resistance by artificial infestation. In: AMERICAN SOCHETY OF SUGAR CANE TECHNOLOGISTS PROCEEDINGS, 1:118-120, 1971.

12. MACEDO, N.; MENDES, A. de C.; BOTELHO, P. S. M. Suscetibility of the main commercial sugar cane varieties to the moth borer, Diatraea saccharalis (Fabr., 1794) in the southern-central Brazil. In: CONGRESS OF THE INTERNATIONAL SOCIETY OF SUGAR CANE TECHNOLOGISTS, 16., Săo Paulo, 1977. Proceedings. p.693-701.

13. MARICONI, F. A. M. Inseticidas e seu emprego no combate às pragas. São Paulo, Nobel, 1976, v.2.

14. MATHES, R. \& CHARPENTIER, L. J. Some techniques and observations in studying the resistance of sugarcane varietes to the sugar cane borer in Louisiana. In: CONGRESS OF THE INTERNATIONAL SOCIETY OF SUGAR CANE TECHNOLOGISTS, 11, Mauritius, 1962. Proceedings. p.594-604.

15. W_ _ - Varietal resistance in sugarcane to stalk moth borer. In: WILLIAMS, J. R.; METCALFE, J. R.; MUNGOMER, R. W.; MATHES, R., eds. Pests of sugarcane. New York, Elsevier, 1969. p.175-188.

16. — INGRAM, J. W; HALEY, W. E. Preliminary report on studies of progenies of sugar cane crosses for susceptibility to sugar cane borer injury in Louisiana. In: CONGRESS OF THE INTERNATIONAL SOCIETY OF SUGAR CANE TECHNOLOGISTS, 6., Louisiana, 1939. Proceedings. p.581-589.

17. PAINTER, R. H. Insect resistance in crop plants. Kansas, University Press, 1968. 520p.

18. PLANALSUCAR. Relatório anual 1977. Piracicaba, Instituto do Açúcar e do Alcool, 1978. 100p.

19. PlaANALSUCAR. Relatório anual 1978. Piracicaba, Instituto do Açúcar e do Alcool, 1980. 98p.

20. REZENDE, J. A. M.: ROSSETTO, C. J.; GERMEK, E. B. Incidência de Saccharicoccus sacchari (Cockerell, 1895) (Homoptera, Coccoidea, Pseudococcidae) em variedades de cana-de-açúcar. Bragantia, Campinas, 38:XXXVII-XI, 1979. (Nota, B)

21. TERAN, F. O. \& NOVARETTI, W. R. Management of populations of Diatraea saccharalis (Fabr., 1794) (Lepidoptera: Crambidae) in sugar cane fields of Sáo Paulo, Brazil. In: CONGRESS OF THE INTERNATIONAL SOCIETY OF SUGAR CANe TEChNologists, 16., São Paulo, 1977. Proceedings. p.671-687. 